\title{
Resistência política, redes intelectuais e atividades editoriais no exílio durante a ditadura militar chilena
}

\author{
Resistance political, intellectual networks and editorial activities in the exile during the
}

Military Dictatorship in Chile

Raphael Coelho Neto

Doutorando em História da Universidade Federal de Minas Gerais raphaelcneto@yahoo.com.br

\begin{abstract}
Resumo: Intelectuais e políticos, a maioria deles ligados a partidos de esquerda no Chile, após o golpe de 1973, tiveram de sair do país rumo a destinos diversos. Desde o exílio, estabeleceram formas de sociabilidade e solidariedade que possibilitaram a formação de redes intelectuais e políticas de oposição à ditadura militar. Neste artigo, traçamos como objetivo central apontar e refletir sobre algumas atividades editoriais do exílio chileno, iniciativas que contemplaram a fundação de editoras e a publicação de importantes revistas e livros em países como Estados Unidos, Canadá, México, França, Itália e Espanha. Não tivemos a pretensão de elencar e analisar todo o universo editorial proporcionado pelos intelectuais exilados, mas, sim, apontar para algumas experiências que certamente evidenciaram práticas marcantes do exílio chileno, indicando possibilidades de atuação conjunta de modo a resistir à ditadura de Augusto Pinochet.
\end{abstract}

Palavras-chave: Ditadura Militar no Chile, Exílio Chileno, Atividade Editorial, Redes Intelectuais.

\begin{abstract}
Intellectuals and politicians, most of them linked to leftist parties in Chile, had to leave the country for various destinations, after the 1973 coup. From the exile, they established ways of sociability and solidarity that enabled the formation of intellectual networks of political opposition to the military dictatorship. In this article, we aimed to detail and reflect on some editorial activities of the Chilean exile, initiatives that included the founding of publishing houses, and the publication of important magazines and books in countries such as the United States, Canada, Mexico, France, Italy and Spain. We did not pretend to list and analyze the entire editorial universe provided by the exiled intellectuals, but rather to highlight some experiences that certainly showed a remarkable practice of Chilean exile, indicating possibilities of joint action in order to resist the dictatorship of Augusto Pinochet.

Keywords: Military Dictatorship in Chile, Chilean Exile, Editorial Activity, Intellectual Networks.
\end{abstract}


Neste artigo, adotamos como proposta de estudo refletir sobre o exílio chileno sob a ótica conceitual de redes intelectuais, que teriam viabilizado a resistência cultural e política dos exilados por meio de atividades e empreendimentos editoriais em distintos lugares do exílio, durante a ditadura militar no Chile. Nossa intenção consiste em apontar e compreender formas de organização política e cultural de parte da intelectualidade chilena exilada, enfatizando a fundação de editoras, a criação de revistas e a publicação de livros.

Dentro da perspectiva da história dos livros e da leitura, não serão objeto de preocupação as formas de recepção da mensagem das revistas e/ou dos livros por parte dos leitores. Portanto, a análise de todo o circuito do processo de comunicação, como sugeriu Robert Darnton (2010), envolvendo autores, editores, aparato de impressão, distribuidores, livreiros (comerciantes e livrarias), até atingir a recepção dos leitores, demandaria um procedimento metodológico complexo que, nesta proposta de trabalho, não poderemos explorar. Para este estudo, pretendemos compreender, de maneira especial, os dois primeiros elementos do processo de comunicação indicado por Darnton, sem sermos negligentes às demais etapas do circuito. O objetivo central consiste em fazer um levantamento parcial de editoras, autores, livros e revistas, analisando um pouco mais acerca de algumas iniciativas e refletindo de uma maneira mais geral sobre as formas de produção e de conteúdo dos impressos no exílio. Partimos da compreensão de que a atividade editorial, sob a condição do desterro político, foi uma forma possível de atuação política e cultural de modo a resistir à ditadura de Augusto Pinochet no Chile (1973-1990), além de possibilitar a formação de vínculos identitários e redes de sociabilidade e solidariedade entre os exilados.

Começamos por apresentar nosso entendimento acerca da condição do exílio, central para a proposta que buscamos desenvolver no artigo. Após a ruptura democrática pelos militares no Chile em 11 de setembro de 1973 e o estabelecimento da brutal repressão e autoritarismo do Estado com a Junta Militar no poder, parte considerável dos perseguidos políticos foi obrigada a deixar o país para os destinos mais diversos, com destaque para a Argentina (até o golpe militar de 1976), a Venezuela, o México, o Canadá, os Estados Unidos, a França, a Espanha, a Suécia, a Itália, a Alemanha Oriental e a União Soviética.

O exílio foi uma necessidade para muitos intelectuais e políticos de esquerda e centro-esquerda, que não tardaram a buscar nos países de acolhida condições para viver, 
produzir e atuar politicamente. Na perspectiva de Loreto Rebolledo González, “jamás en la historia de Chile se había registrado una salida forzada de chilenos tan masiva en tan corto plazo y hacia lugares tan diversos como la iniciada a partir de septiembre de 1973" (REBOLLEDO GONZÁLEZ, 2012: 178). Como afirmou Pablo Yankelevich (2011), o exílio chileno foi altamente politizado, pelo fato de que muitos dos que deixaram o país terem sido dirigentes políticos - a maioria deles ligada ao governo socialista de Salvador Allende -, militantes ou seguidores dos partidos da Unidade Popular (UP), que pronto se articularam em redes transnacionais para combater a ditadura. A condição de exílio dos chilenos, portanto, foi resultado de uma atuação extremamente violenta de parcela importante dos militares e da direita chilena no sentido de destruir o projeto socialista que se tentava implementar através do Estado e dos mecanismos constitucionais. Saíram do Chile, dessa maneira, "os sobreviventes de um governo e milhares de seus simpatizantes" (YANKELEVICH, 2011: 15-16), além de alguns políticos e intelectuais progressistas de partidos de centro, como a Democracia Cristã (DC), que se opuseram ao golpe e à ditadura.

Sobre o exílio, Mario Sznajder e Luis Roniger, dentro de uma perspectiva sociopolítica de análise, entenderam-no como um mecanismo institucionalizado de exclusão política, social e cultural mediante o qual cidadãos envolvidos na política ou na vida pública são forçados a abandonar seu país de origem, impossibilitados de regressar até que se tenham alterado as circunstâncias políticas (SZNAJDER \& RONIGER, 2013: 31). Tal procedimento teria o intuito de manter o controle da esfera pública, por parte do Estado, condenando ao desterro e, por conseguinte, à perda de direitos civis aqueles que, de alguma forma, posicionaram-se contrários às políticas oficiais e ao status quo. Essa definição abarcaria tanto quem sofreu perseguição direta das autoridades e agentes a serviço do Estado (ou de atores políticos violentos, como os grupos paramilitares), quanto aqueles que escolheram sair do seu país por sentirem-se ameaçados ou por atravessarem problemas existenciais que se originaram no político. Dessa maneira, na visão dos dois autores, o sentido de coação e a ameaça à integridade física seriam os fatores principais que marcariam a necessária saída do território de um Estado.

Interessante observarmos, portanto, a partir desse tipo de interpretação, o fator político como central para o trabalho conceitual com o termo exílio. Além disso, como desenvolveram Sznajder e Roniger, o exílio pressupõe, por parte daqueles que o sofrem, o sentido de uma condição adversa temporal e passageira, o que provocaria nos 
exilados, em tese, uma atitude de resistência à mera aculturação e adaptação ao país que os recebeu. Assim, persistiria neles o desejo de um retorno imediato a seu país de origem. A proibição oficial efetiva de retorno do indivíduo ao país natal, por parte do governo vigente, pareceu-nos ser uma condição marcante da experiência do exílio (RONIGER, 2011: 40).

Todavia, a despeito de partirmos do pressuposto de sua condição ser política, qualquer generalização conceitual sobre o exílio, a priori, sem a devida historicidade do termo, poderia incorrer em precipitação de nossa parte. As categorias que objetivam definir a especificidade do exílio e dos exilados, na realidade, podem se confundir nas comunidades deslocadas, possibilitando a cada indivíduo vivenciar distintas etapas em seu caminho seguido fora das fronteiras dos Estados de origem. Assim, tornar-se-ia difícil e, por vezes, quase inútil, a suposta identificação antecipada entre refugiados, migrantes e exilados, por exemplo. Caberia, portanto, a observação da interação específica desses indivíduos "nas comunidades diaspóricas e as relações entre sua situação em lugares de reinstalação e redes transnacionais", o que poderia ajudar a definir o caráter particular em cada movimento de saída forçada (RONIGER, 2011: 44).

Nesse sentido, a perspectiva de categorização dos desterrados pode partir dos próprios sujeitos históricos que sofreram essa experiência. Sznadjer e Roniger citaram, por exemplo, o ponto de vista do intelectual naturalizado chileno Ariel Dorfman. Sendo apresentado aos benefícios materiais que a condição de refugiado possibilitaria, de acordo com o Estatuto da ONU de 1951, tais como atenção médica, capacitação para inserir-se em um emprego e cursos de idioma do país de asilo, Dorfman optou, deliberadamente, por ser um exilado. Sua escolha se justificou por entender que a condição de exilado se contrapunha à de refugiado por ser mais ativa, carregando um sentido que o projetava para sua "odisea como algo que se originaba en mí mismo y no en las fuerzas históricas que bullían fuera de mí alcance" (DORFMAN apud SZNAJDER \& RONIGER, 2013: 50-51). Percebe-se nessa autoproclamação de exilado do escritor chileno uma tentativa de manter certa autonomia sobre sua condição de desterrado e perseguido político, adotando uma atitude ativa de combate à condição política vigente em seu país, no caso, a ditadura militar de Augusto Pinochet.

A postura de Ariel Dorfman alinhou-se com aquilo que Mario Sznajder e Luis Roniger conceberam conceitualmente para o exilado, qual seja, a sua vontade, ainda que limitada, de manter o controle sobre suas decisões vitais. Pensamos que esse tipo de conduta condiz com a resistência de intelectuais e políticos chilenos no exílio, ao 
buscarem, por exemplo, a efetivação de atividades editoriais de claro teor político e cultural combativo em relação à repressão exercida pelo governo de Pinochet. Tais condutas proativas de resistência dos exilados chilenos podem ser interpretadas como um processo desencadeado pela reflexão e redefinição da identidade dos indivíduos no exílio, operando-as na elaboração de tendências civis e políticas que se consubstanciariam em ativismo político (SZNAJDER \& RONIGER, 2013: 54).

Através de encontros culturais, dos congressos acadêmicos, da fundação de editoras, da criação de selos musicais e de rádios e da publicação de revistas, além da atuação dos tradicionais partidos políticos de esquerda, parte substancial da comunidade chilena exilada consolidou a formação de redes transnacionais tramadas com laços fortalecidos, o que contribuiu para robustecer a resistência ao governo pinochetista. $\mathrm{O}$ sentido de formação de redes no exílio chileno consistiu não somente em "ayudarse y reforzar una identidad, sino para denunciar lo que ocurría en Chile", afirmou a historiadora e antropóloga chilena Loreto Rebolledo González (2012: 183). Por redes intelectuais entendemos "una forma de sociabilidad y una cadena de contactos e interacción entre artistas, gente de letras, editores y otros tipos de agentes culturales, ligados por convicciones ideológicas o estéticas compartidas" (ALTAMIRANO, 2010: 18-19), embora essa condição, que pressupõe certa unidade, não elimine as divergências dentro dos grupos, os conflitos internos e externos, políticos e/ou culturais. Álvaro Fernández-Bravo (2011) e Adriane Vidal Costa (2018) sublinharam um aspecto que consideramos relevante pensar, o de que a noção de redes sugere a proeminência do caráter relacional e dialógico intersubjetivo, implicando o intercâmbio de ideais, conceitos, valores e bens simbólicos entre um grupo ou comunidade intelectual, restituindo a historicidade dos encontros e da circulação de ideias. Partimos do pressuposto de que o surgimento de editoras e de publicações (livros e revistas) efetivarse-ia a partir exatamente do necessário caráter relacional de iniciativas coletivas, conformando projetos em que seus colaboradores somente poderiam atuar em redes que demandariam certa frequência de contato, compartilhando afinidades eletivas, em movimentos de convergência e atração recíprocas. As formas de relação entre aqueles que as integram podem ser variadas, abarcando os contatos pessoais; os encontros nos mesmos congressos, eventos e espaços de trabalho, como a redação de um impresso periódico; as publicações e os debates nas páginas de uma revista ou jornal; os comentários, prólogos ou resenhas em livros; as citações recíprocas; os diálogos e as polêmicas (DEVÉS-VALDÉS, 2007: 30-32). 
O sentido de interação, circulação e intercâmbio cultural e de ideias, presente no conceito de rede, nos leva a uma abordagem transnacional da pesquisa, visto que tal possibilidade de análise metodológica se volta para as zonas de contato, nas quais os encontros, que extrapolam os espaços nacionais, transparecem como comunidades de discurso. A abordagem transnacional, portanto, revela-nos a permeabilidade das fronteiras (nacionais, regionais etc) e a intensa circulação de corpos, ideias e informações. O exílio, por exemplo, carrega como marca fundamental de sua condição o caráter transnacional das redes de contato, do compromisso e militância política, das várias formas de movimento e identidade, característica do próprio fenômeno da migração, como bem expressou Barbara Weinstein a respeito (2013: 13-29).

O crítico literário argentino Noé Jitrik, assim como Pablo Yankelevich, como mencionamos, também defendeu a ideia de um exílio chileno ativo, resistente e politizado. Segundo ele, os escritores e os intelectuais do Chile, de uma maneira geral, vivenciaram a experiência do exílio como uma espécie de "prolongação de um compromisso estabelecido anteriormente com seu país" (JITRIK apud VIDAL, 2004: 40). Em nosso entendimento, essa não foi uma particularidade chilena, mas foi uma característica que os marcou especialmente, pelo fato de, até o momento do golpe, encontrarem-se lado a lado ou partícipes da construção do socialismo a partir do Estado.

Antes de partirem para o exílio, muitos intelectuais (em muitos casos também políticos, dirigentes ou com alguma vinculação partidária) tiveram importante experiência acadêmica e/ou editorial no Chile antes e durante a Unidade Popular e o governo de Salvador Allende. A aproximação efetiva do povo chileno à cultura, tentada durante a presidência de Allende, consolidou-se principalmente através da indústria editorial, por exemplo, em especial por meio da Editorial Nacional Quimantú. Sob o controle estatal, este empreendimento editorial se transformou no principal aparato de produção de conteúdos culturais, carregando em si uma lógica de responsabilidade social. Nos dois últimos anos da UP, Quimantú, com uma linha extensionista, produziu massivamente livros pensados para vários setores da sociedade chilena, distribuídos a preços muito baixos, fazendo frente aos editoriais do setor privado e gerando novas dinâmicas de distribuição, consumo e leitura de livros. ${ }^{1}$ Importante lembrar também que

\footnotetext{
${ }^{1}$ Ver ALBORNOZ, César (2005). La cultura en la Unidad Popular: porque esta vez no se trata de cambiar un presidente. In: VALLEJOS, Julio Pinto (org). Cuando hicimos historia: la experiencia de la Unidad Popular. Santiago: LOM Ediciones, pp. 147-176; SUBERCASEAUX, Bernardo (2010). Historia del libro en Chile: desde la Colonia hasta el Bicentenario. Santiago: LOM Ediciones.
} 
Santiago de Chile foi a sede de centros acadêmicos e de formulação de políticas públicas de prestígio, como a CEPAL e a FLACSO. ${ }^{2}$

Atuando no Estado ou fora dele, contribuindo diretamente com projetos de transformação social desde o governo do democrata-cristão Eduardo Frei Montalva (1964-1970), intensificados após a eleição de Salvador Allende, muitos intelectuais e políticos possuíram trajetórias como editores, escritores, articulistas e/ou professores acadêmicos, nas quais, obviamente, perpassaram a produção, edição e publicação de livros e revistas. Foram verdadeiros mobilizadores sociais, muitos com reconhecido capital acadêmico, político e cultural, exercendo, pelo menos desde esse período, trabalhos de mediação intelectual combinados à intensa atividade política. Interpretamos que tais experiências acadêmica e editorial prévias teriam sido importantes, não necessariamente decisivas, para certa continuidade desse trabalho, impulsionando iniciativas formuladas e adaptadas à realidade da repressão política e do exílio, dessa vez em uma perspectiva transnacional de contatos e circulação de ideias.

Pensarmos a esse respeito não deve negligenciar, muito antes o contrário, a importante colaboração, em muitos casos oficial e institucional, dos países anfitriões em relação aos exilados chilenos. Os espaços de recepção guardavam diferenças que passavam pelos grupos políticos no poder e as particularidades históricas que conferiam maior ou menor possibilidade de integração e atuação por parte dos exilados. Nesse sentido, o México se destacou historicamente como lugar de refúgio e asilo, sobretudo durante as ditaduras no Cone Sul. Casa de Chile, espaço político criado em 1974 para os partidos de esquerda do Chile, contou com o compromisso direto do presidente mexicano Luis Echeverría Álvarez (1970-1976). Na Europa, Paris foi um dos mais importantes lugares do exílio chileno, onde foi criada a importante revista Araucaria de Chile, da qual trataremos adiante. Também a Suécia exerceu papel central, país orientado para uma política oficial de recepção e integração dos exilados. Diferentemente da capital francesa, por exemplo, que recebeu uma diversidade de chilenos, outros lugares foram marcados por especificidades em razão do perfil político dos exilados. Foi o caso dos comunistas chilenos que, em grande medida, estiveram na URSS, e dos socialistas na Alemanha Oriental. Os democratas-cristãos e a esquerda

\footnotetext{
${ }^{2}$ Sobre o peso do campo acadêmico chileno como centro periférico regional, sobretudo no campo das ciências sociais, ver BEIGEL, Fernanda (Directora) (2010). Autonomía y dependencia académica. Universidad e investigación científica en un circuito periférico: Chile y Argentina (1950-1980). Buenos Aires: Biblos.
} 
chilena oriunda da Democracia Cristiana (DC), como alguns integrantes do Movimiento de Acción Popular Unitaria (MAPU) e também da Izquierda Cristiana (IC), tiveram boa acolhida pelo governo da DC italiana. Desse contexto resultou outra relevante revista do exílio, Chile-América, como também veremos. ${ }^{3}$

De uma maneira geral, a recepção e as possibilidades de atuação de muitos intelectuais e políticos chilenos no exílio podem ser explicadas, em boa medida, pelas simpatias angariadas junto aos europeus, especialmente, em razão do interesse ao projeto de socialismo por vias democráticas da Unidade Popular. Também podemos pensar em uma solidariedade internacional sensibilizada pela morte traumática de Salvador Allende e o amplo repúdio gerado pela forma altamente violenta com que a Junta Militar desfechou o golpe de Estado no Chile. Por fim, ligado a este último aspecto, a maneira extremamente autoritária com que Augusto Pinochet exerceu seu poder no país recrudesceu a recepção aos exilados e a denúncia que poderiam efetivar de diversas formas, incluindo o campo da edição de livros e impressos periódicos, alertando sobre a prática sistemática de violação aos direitos humanos no Chile. Rebolledo González indicou que, principalmente por parte dos intelectuais,

la articulación entre cultura y política fue el modo de preservar el vínculo con Chile y el testimonio cotidiano con la lucha y resistencia contra la dictadura, pero además fue la forma de hacer explícita una identidad propia frente a las otras comunidades de exiliados y los habitantes del país de recepción. Ello se vio facilitado por la amplitud del exilio, que incluyó a numerosos intelectuales y artistas, y también por la capacidad organizativa que los exiliados llevaron en sus maletas y que habían aprendido en su práctica política en Chile (REBOLLEDO GONZÁLEZ, 2012: 183).

Vejamos, então, mais detidamente, sobre o universo editorial chileno no exílio resultante das iniciativas de resistência cultural e política à ditadura militar, mobilizando

\footnotetext{
${ }^{3}$ Ver SZNAJDER, Mario \& RONIGER, Luis (2013). La política del destierro y el exilio en América Latina. México: Fondo de Cultura Económica; ROJAS MIRA, Claudia Fedora. El exilio político chileno: la Casa de Chile en México (1973-1993), una experiencia singular (2013). Universidad de Santiago de Chile, Faculdad de Humanidades; ROJAS MIRA, Claudia Fedora; SANTONI, Alessandro (2013). Geografía política del exilio chileno: los diferentes rostros de la solidariedad. Perfiles Latinoamericanos, n. 41, pp. 123-142, enero/junio; ULIANOVA, Olga (2013). El exilio comunista chileno. Estudos IberoAmericanos, PUCRS, v. 39, n. 2, pp. 212-236, jul./dez.
} 
a opinião pública internacional por meio de informações e denúncias da violência política articuladas em redes intelectuais.

\section{Política e edição de revistas e livros no exílio}

As revistas culturais de exílio Literatura Chilena e Araucaria de Chile não apenas foram importantes iniciativas editoriais, como também cumpriram papel fundamental na organização e na articulação da intelectualidade chilena de esquerda, em especial socialistas e comunistas. Elas não apenas deram vazão, em suas páginas, a debates significativos sobre questões diversas - todas relacionadas, em maior ou menor grau, com a cultura chilena e a resistência política -, como promoveram e/ou divulgaram eventos importantes organizados pelos intelectuais exilados junto à comunidade internacional, visando chamar a atenção da opinião pública de países distintos, sobretudo na Europa e nas Américas.

Literatura Chilena foi uma revista de periodicidade trimestral publicada em Los Angeles, nos Estados Unidos, pelos críticos, escritores e editores chilenos Fernando Alegría e David Valjalo. Foi editada e publicada no exílio pela editora Ediciones de la Frontera, entre 1977 e 1989, mudando a sede de sua redação de Los Angeles para Madrid em 1985, concentrando os trabalhos de edição na figura de Valjalo. Nascida como Literatura Chilena en el Exilio, a revista, em 1981, passou a se chamar Literatura Chilena, Creación y Crítica, entendendo que deveria divulgar a cultura chilena não apenas do exílio, mas também aquela advinda do Chile, de teor, obviamente, crítico à ditadura. Originou-se de redes (e, ao mesmo tempo, ajudou a consolidá-las) de críticos, escritores e acadêmicos chilenos que se exilaram nos Estados Unidos e no Canadá. Tais redes, como explicou Rubí Carreño (2009: 132), foram possibilitadas por três fatores centrais, a saber, a de "intelectuales chilenos que ya se encontraban trabajando en ese país [como foram os casos de Fernando Alegría e David Valjalo]; [...] de los críticos que poseían el grado de doctor otorgado por universidades de primer nivel y a la solidaridad de los académicos y jefes de departamento norteamericanos". A sociabilidade intelectual da qual Literatura Chilena fez parte possuiu um caráter acadêmico, embora ela tenha sido uma revista cultural de predominante conteúdo literário.

Araucaria de Chile, por sua vez, foi fundada e publicada em Paris por intelectuais comunistas exilados, com destaque para o importante político e escritor 
Volodia Teitelboim e o editor e escritor Carlos Orellana, respectivamente, diretor e editor da revista. Teitelboim vivia em Moscou, e Araucaria, embora circundada, na capital francesa, por intelectuais de renome como Julio Cortázar, importante colaborador da revista, extrapolou as fronteiras daquele país por dialogar especialmente com os comunistas chilenos espalhados pelo exílio, localizados especialmente na URSS. Tratou-se de uma revista de densidade, que proporcionou ampla divulgação da produção cultural chilena e latino-americana no exílio, com cerca de 220 páginas em cada edição. Ediciones Michay foi a editora através da qual foi editada Araucaria, cuja existência compreendeu os anos de 1978 até 1990, tendo, em 1984, um ano antes de Literatura Chilena, portanto, estabelecido sua redação em Madrid, demonstrando ter sido a capital da Espanha outro centro de convergência de intelectuais chilenos no exílio.

Ambos os impressos, Araucaria e Literatura Chilena, destacaram-se pela veiculação e divulgação de uma produção cultural chilena de resistência política à ditadura pinochetista, com destaque para as artes plásticas, a música, o cinema, o teatro e a literatura. As editoras que produziram as revistas e foram criadas e administradas pelos editores responsáveis por Literatura Chilena e Araucaria de Chile, respectivamente, David Valjalo e Carlos Orellana, possibilitaram a reunião de escritores, artistas, críticos e estudiosos, contribuindo para a formação e/ou consolidação de redes intelectuais.

Ediciones de la Frontera foi uma editora pequena, criada por Valjalo em Los Angeles e que se dedicou à publicação trimestral de Literatura Chilena en el Exilio/Literatura Chilena, Creación y Crítica entre 1977 e 1987. No exílio, o editorial ainda se prestou à organização de duas coletâneas de poemas, publicadas nos dois anos seguintes, 1988 e 1989. Ainda que modesta do ponto de vista econômico, Ediciones de la Frontera editou e promoveu obras literárias de escritores chilenos exilados, dentre os quais alguns que debutavam no ofício como forma de se opor cultural e politicamente à ditadura.

Em seu número 6, de 1978, Literatura Chilena en el Exilio divulgou obras de poucas páginas e a preços módicos, impressas por Ediciones de la Frontera de maneira, aparentemente, rudimentar. Anunciou-se Lament for Chile, do poeta Jaime Valdivieso, edição bilíngue em espanhol e inglês, de apenas 20 páginas, em formato reduzido, custando U\$ 1. Com o mesmo valor e com características materiais similares, também se anunciou uma pequena antologia de poemas do próprio David Valjalo, denominada Trece poemas, de 24 páginas. Ademais, foram divulgadas obras que estariam em 
distribuição pela pequena editora: Una vida por la legalidad (1976), memórias do general constitucionalista Carlos Prats - morto em um atentado cometido pelas forças de inteligência e repressão da ditadura chilena, a DINA, em Buenos Aires, no ano de 1974 -, livro publicado postumamente; e Literatura y revolución (1971), de Fernando Alegría. Ambas as obras foram editadas pela importante editora mexicana Fondo de Cultura Económica ${ }^{4}$ (LITERATURA CHILENA EN EL EXILIO, 1978: s.p.).

$\mathrm{Na}$ edição seguinte da revista, novos livros encontraram-se em distribuição: Relato en el frente chileno, de 1978, narrativa testimonial do jovem escritor que se apresentava sob o pseudônimo Ilario Da; e Los trabajos y los días de Recabarren, de 1977, do historiador e professor Alejandro Witker, sobre o fundador do Partido Comunista chileno, Luis Emilio Recabarren. Os valores destas duas últimas obras publicadas no exílio foram de U\$ 5 e U\$ 3,50, respectivamente. Na edição de número 8, apareceram muitos outros títulos em distribuição pela Ediciones de la Frontera. Além das obras mencionadas, destacamos Confieso que he vivido (1974), memórias póstumas do poeta Pablo Neruda; Los poetas chilenos luchan contra el fascismo (1977), antologia, organizada por Sergio Macias, de poemas-testemunhos feitos nas prisões políticas chilenas; o testemunho Prisión en Chile (1975), de Alejandro Witker; El teatro latinoamericano de lucha popular, do acadêmico Pedro Bravo-Elizondo; Dialéctica de una derrota (1979), do dirigente socialista Carlos Altamirano; e Conversarciones con Allende (1971), do intelectual francês Régis Debray (LITERATURA CHILENA EN EL EXILIO, 1978: s.p.). ${ }^{5}$ Em sua edição de número 16, de 1981, já como Literatura Chilena, Creación y Crítica, realçamos o anúncio e distribuição do livro de contos literários Las malas juntas (1978), do então jovem escritor chileno José Leandro Urbina, editada pela Ediciones Cordillera, editora criada por exilados chilenos em Ottawa, no Canadá.

\footnotetext{
${ }^{4}$ Informação a respeito do livro Una vida por la ledalidad é importante destacar. Citamos Claudia Fedora Rojas Mira (2013: 119-120), que, em seu estudo, afirma: “[...] Ejemplo interesante de esta gran apertura y sensibilidad a la causa chilena, de parte del régimen político mexicano, [...] se trata de la edición por parte del Fondo de Cultura Económica (FCE), editorial estatal, de las memorias apócrifas del general Carlos Prats González. Luego de su asesinato en Buenos Aires, el Partido Comunista chileno a sabiendas que el desaparecido oficial de ejército había estado escribiendo sus memorias, decidió escribir unas falsas. Así, esta tarea le fue encomendada al periodista y escritor Eduardo Labarca Goddard, quien décadas más tarde develó el verdadero origen de tales memorias. El FCE editó cien mil ejemplares del apócrifo texto y los distribuyó por el mundo entero. Además, el libro fue presentado formalmente en la Casa de Chile en México el 12 de febrero de 1977, con el título Una vida por la legalidad del ya citado general".

${ }^{5}$ Esses títulos, acrescidos de um ou outro igualmente voltados para a literatura e para o debate político das (e sobre as) esquerdas, como El libro negro de la intervención norte-americana en Chile (1974), de Armando Uribe, apareceram em anúncio nas edições de número 9, 11, 12 e 13 de Literatura Chilena en el Exilio.
} 
Sobre este projeto editorial, Ediciones Cordillera, Literatura Chilena destacou a capacidade de mobilização dos chilenos exilados naquele país (LITERATURA CHILENA EN EL EXILIO, 1978: 33). Na seção Documentos da revista, foi publicado um informe da Asociación de Chilenos de Ottawa, no qual se anunciou a criação de Ediciones Cordillera, que tinha como objetivo a publicação de livros de chilenos exilados, bem como daqueles que permaneceram no país, mas que, todavia, pouco espaço possuíam para a expressão literária crítica e criativa. Os membros do Comitê da nova editora creditaram a criação da mesma à necessidade de divulgação do patrimônio artístico e cultural do Chile, buscando restabelecer o diálogo entre os escritores e o público do país, fragmentado pela repressão política. A nota informou também sobre a presença de destacados intelectuais chilenos na composição do Conselho Consultivo da editora, como Fernando Alegría, fundador de Literatura Chilena, Jaime Concha e Antonio Skármeta, críticos e escritores importantes, colaboradores também das revistas Literatura Chilena e Araucaria de Chile. Ainda de acordo com o informe, os primeiros livros lançados pela Ediciones Cordillera foram Las malas juntas, de José Leandro Urbina, como havíamos mencionado, obra que reuniu contos de alto teor político; Poemas, de Jorge Etcheverry; e La Ciudad, de Gonzalo Millán, estes dois últimos proeminentes poetas chilenos, cujos textos foram frequentemente publicados por Literatura Chilena e Araucaria de Chile, evidenciando uma rede de atores, contatos e diálogos comuns e de reciprocidade entre projetos editoriais distintos.

A editora Ediciones Michay, até 1984, quando Araucaria de Chile encontrava-se em Paris, dedicou-se à publicação da revista. Nesse ano, a mudança definitiva da redação de Araucaria de Chile para Madrid efetivou-se em razão de poder se concentrar na capital espanhola todo o processo de edição, impressão e distribuição realizado por Ediciones Michay, tendo em vista que a editora passou a atuar também na edição e impressão de livros de chilenos exilados. Antes, porém, assim como Ediciones de la Frontera, Ediciones Michay atuara na distribuição de obras publicadas por outras editoras e selos editoriais.

A edição de número 25 de Araucaria de Chile, por exemplo, anunciou uma série de livros que poderiam ser enviados aos leitores da revista pelos serviços de distribuição da editora. Dentre eles, encontravam-se Santiago-Moscú-Santiago (apuntes del exilio) (1983), de Luis Corvalán, Secretário-geral do Partido Comunista chileno; Víctor Jara. Un canto truncado (1983), de Joan Jara, viúva do músico comunista assassinado pelas forças repressivas da ditadura militar; La casa de los espíritus (1982), da escritora 
chilena Isabel Allende; Nicaragua tan violentamente Dulce (1983), do renomado escritor argentino Julio Cortázar; Cantores que reflexionan. Notas para una historia personal de la Nueva Canción Chilena (1984), de Osvaldo Rodríguez; Del fetichismo de la mercancía al fetichismo del capital (1982), de Osvaldo Fernández, filósofo e membro do Conselho Editorial de Araucaria de Chile; Los enganchados de la era del salitre (1983), de Pedro Bravo-Elizondo; Soñé que la nieve ardía (1975), do escritor Antonio Skármeta; e La guerra interna (1979), do diretor de Araucaria Volodia Teitelboim (ARAUCARIA DE CHILE, 1984: 224).

Tal qual a amplitude na abordagem temática da produção cultural e intelectual chilena do exílio nas páginas da revista Araucaria de Chile, as obras distribuídas e, posteriormente, os livros publicados pela editora Ediciones Michay versavam sobre política, sociedade e cultura do Chile. A série de livros publicados, a partir de 1984, pela editora de Araucaria, inseriu-se na coleção Libros del Meridión, cujo nome, como explicou Carlos Orellana, fazia referência aos livros produzidos por escritores nascidos no sul (meridional), ou seja, no Chile (ORELLANA, 1984: 192). As três primeiras obras anunciadas em Araucaria de Chile foram Neruda, biografia de Volodia Teitelboim sobre o poeta chileno; El libro mayor de Violeta Parra, de Isabel Parra, filha da importante compositora chilena que dá nome ao título do livro; e Dawson, testemunho sobre a experiência na prisão política situada no inóspito extremo sul chileno (Isla Dawson), do filósofo e político comunista Sergio Vuscovic' Rojo. Em cada anúncio das obras estavam contidos seu resumo, formato, quantidade de páginas e valor para compra (ARAUCARIA DE CHILE, 1984: 223).

Na edição de número 35 da revista Araucaria de Chile, de 1986, novos títulos foram anunciados pela série Libros del Meridión. Dentre eles, encontravam-se Muerte y resurrección del teatro chileno (1973-1983), do crítico literário Grinor Rojo; Cultura y teatro obreros en Chile, de Pedro Bravo-Elizondo; Actas del Alto Bío Bío, do músico e escritor Patricio Manns; e El movimiento obrero en Chile: antecedentes (1891-1919), de Fernando Ortiz Letelier, professor da Universidad de Chile até 1973 e membro do Comitê Central do PCCh, desaparecido desde dezembro de 1976, provavelmente assassinado por agentes da DINA (ARAUCARIA DE CHILE, 1986: 222-223). Nota-se, portanto, que os livros publicados ou divulgados por Ediciones Michay foram obras marcadamente políticas, cujos autores, temas ou personagens históricos retratados estiveram diretamente vinculados às esquerdas chilenas, principalmente ao Partido Comunista, ao qual a revista Araucaria de Chile estava ligada, já que era financiada por 
ele e dirigida por dois nomes de suas fileiras, sendo um deles de grande prestígio político, Volodia Teitelboim.

A maioria das obras distribuídas e/ou publicadas por Ediciones de la Frontera e por Ediciones Michay foram também analisadas, por meio de resenhas críticas ou de ensaios, em Literatura Chilena e em Araucaria de Chile, algumas delas em ambas as revistas. Como pudemos perceber pelos títulos dos livros, as duas editoras priorizaram a divulgação e/ou publicação de obras de exílio de caráter cultural e político, que ora denunciavam os crimes praticados pela ditadura chilena ora resgatavam valores pertencentes às culturas políticas socialista e comunista no Chile, através dos quais se buscava forjar a identidade chilena. Acreditamos que seus editores, colaboradores e autores estavam inseridos em uma rede intelectual que os aproximou, sobretudo, pela resistência cultural e pelo compartilhamento de valores políticos de esquerda. Nesse sentido, podemos afirmar que as editoras, assim como as revistas, foram promotoras de redes intelectuais de resistência à ditadura que se edificaram no exílio, seja pelo compartilhamento de ideias, pelas citações recíprocas, seja pelos contatos frequentes em encontros, eventos culturais e/ou nas sedes das redações.

Literatura Chilena e Araucaria de Chile se destacaram pela publicação de contos, poemas e trechos de obras literárias, publicadas no exílio, de teor e estética altamente políticos. Nesse aspecto, enfatizamos a ampla divulgação que deram à literatura testemunhal ou de testimonio. Não cabe neste artigo elencar e analisar as muitas narrativas de testemunho nas revistas. A modo de exemplo, daremos ênfase ao citado testimonio de Sergio Vuscovic' Rojo, Dawson, publicado em 1980 na Itália, onde seu autor encontrava-se exilado. Posteriormente, essa obra foi publicada também por Ediciones Michay, como mencionamos.

Vuscovic' Rojo permaneceu detido pelos militares por um longo tempo em Isla Dawson, prisão política aberta durante a ditadura no extremo sul do Chile, em uma antiga base para acampamento de engenheiros da Armada chilena. Ali, ele conviveu com importantes dirigentes dos partidos que integraram a Unidade Popular, como Luis Corvalán, do Partido Comunista, e com ex-ministros e membros do governo de Salvador Allende, como José Tohá, Orlando Letelier, Miguel Lawner, Sergio Bitar e Clodomiro Almeyda, este último, histórico dirigente do Partido Socialista. Em meio ao relacionamento com os companheiros presos, as humilhações sofridas diante dos militares e os trabalhos forçados, Sergio Vuscovic' Rojo escrevia, em manuscritos, suas observações da vida diária em Dawson. Dessas anotações e intercalando-as com 
fragmentos de testimonios de outros prisioneiros políticos, como Orlando Letelier, Clodomiro Almeyda e Osvaldo Puccio, foi editado e publicado o livro-testimonio na Itália. Essa obra foi resultado, portanto, da confluência de distintas vozes e experiências, tornando-se espécie de síntese do que teria sido a vida dos confinados em Dawson. Interessa-nos, em especial, o epílogo do livro, denominado por Vuscovic' Rojo de $E l$ espíritu de Dawson, no qual ele esclareceu sobre a experiência coletiva e solidária dos prisioneiros desse "campo de concentração":

No todos comprenden a fondo lo que significa la solidaridad nacional e internacional para el torturado, para que el detenido por años no pierda la fe en sus ideales y en sí mismo. [...] Aún estando solo en una celda uno sabía, con plena certeza, que no estaba solo. Éramos hermanos en esencia, para nosotros mismos y para los demás, incluso hasta para nuestros verdugos. [...] El espíritu de Dawson, es decir: frente a la adversidad, la firmeza, la serenidad, la esperanza, la conducta humana común a los luchadores sociales; la lucha por sobreponerse a la prueba más feroz que pueda afrontar un revolucionario: la de la agresión fascista. El espíritu de Dawson es también, en fin, el afecto, el respeto mutuo, la imborrable hermandad que se establece entre los prisioneiros (VUSCOVIC'ROJO, 1978: 75-76).

Nas palavras do autor, percebemos, mesmo após o duro golpe sofrido pela esquerda chilena com a violenta destituição do governo Allende, a persistência de um ideário político combativo, revolucionário, solidário, que abasteceria a resistência à ditadura e que se reproduziria, naquele momento, paradoxalmente, em um dos poucos espaços possíveis para esse tipo de convivência em um Chile autoritário no imediato pós-golpe, a prisão política.

Para o filósofo italiano Giorgio Agamben, a essência de um campo, seja ele de concentração, de trabalhos forçados, de detenção, de refugiados, consiste na materialização do Estado de exceção e na consequente criação de um espaço para a vida nua como tal, ou seja, uma vida que não é reconhecida em sua forma-de-vida, desprovida, dessa maneira, de sua identidade, cultura e direitos (AGAMBEN, 2015: 45). Assim como os "campos de concentração" da ditadura chilena, acreditamos que o exílio também pode ser pensado como resultado de uma condição em que o ordenamento normal da vida social daqueles que o sofrem é suspenso. Porém, sem amenizar os mecanismos autoritários típicos de Estados de exceção, como a ditadura pinochetista, 
podemos interpretá-lo, no nosso caso, como um espaço transnacional que permitiria uma rearticulação ou reformulação dos projetos políticos e culturais daqueles que se identificavam com o governo socialista e a conjuntura democrática anterior à ascensão dos militares chilenos ao poder.

Nesse sentido, outra iniciativa editorial de grande relevância que se projetou no exílio foi a revista Chile-América. Diferentemente das revistas culturais e políticas Araucaria de Chile e Literatura Chilena, Chile-América foi uma publicação periódica essencialmente política. Fundada na Itália, em Roma, no ano 1974, essa revista nasceu da necessidade de se promover o debate político por meio da publicação de artigos, ensaios, críticas analíticas e programas partidários da oposição à ditadura militar chilena, veiculando em suas páginas não apenas a resistência, mas propostas políticas alternativas ao regime pinochetista. Estiveram à frente desse empreendimento editorial Bernardo Leighton e Esteban Tomic, tradicionais políticos da DC, em especial o primeiro; José Antonio Viera-Gallo, filiado ao MAPU e, a partir de 1987, ao Partido por la Democracia (PPD); e Julio Silva Solar, ligado originalmente ao MAPU e, depois, à IC, partidos que integraram a UP. Como a vinculação política de seus fundadores indica, Chile-América foi "una tribuna abierta para los miembros de la DC chilena e internacional como para miembros de partidos de izquierda que manifestaron su oposición a los militares" (ACERCA DE NOSOTROS, s.d.). Outro nome que figurou como central para Chile-América foi o do jornalista Fernando Murillo Viaña, ganhador do Premio Nacional de Periodismo na categoria Crónica, em 1967. Ele teve um papel fundamental na revista para a consolidação de uma marca de sua linha editorial, que foi a de conseguir, compilar, eventualmente produzir e sistematicamente publicar, parcial ou integralmente, documentos de extrema relevância para o que se propôs ChileAmérica. Assim, ganhou projeção a divulgação e debate dos programas e das posições táticas e estratégicas dos partidos da oposição à ditadura, com destaque para os de esquerda e a DC, assim como circularam, por meio de suas páginas, diversos informes e relatórios oficiais de comissões e organismos de direitos humanos do mundo todo a respeito da ruptura democrática no Chile, da violência institucionalizada e consumada de maneiras trágicas, do atropelo aos direitos básicos dos cidadãos no país.

O primeiro número da revista saiu em setembro de 1974, um ano após o golpe. Sua publicação foi inicialmente mensal, com cerca de 25 a 30 páginas em cada um de seus três primeiros números, passando a ter depois uma circulação trimestral, com edições de dois ou três números, possuindo mais de 200 páginas cada volume. De 
acordo Julio Silva Solar, seu principal editor, a revista circulou em 66 países (SILVA SOLAR, s.d.). Foram editados 89 números até outubro de 1983, quando se encerraram suas publicações.

A aproximação política, no combate à ditadura, entre partidários da UP e democrata-cristãos de tendência mais progressista, dando origem à Chile-América, ficou expressa logo no primeiro número do impresso. Foi publicada uma declaração assinada por Bernardo Leighton e Rafael Augustín Gumucio, ambos fundadores da DC. Leighton, além de destacado político pelo partido, foi vice-presidente do Chile no mandato de Eduardo Frei Montalva. Destacou-se como um democrata-cristão de "avanzadas ideas sociales". Augustín Gumucio, assim como Julio Silva Solar e Jacques Chonchol, pertenceu à ala mais à esquerda da DC que se desmembrou, formando o MAPU, em 1969. Em 1971, descontentes com a linha marxista-leninista adotada por esse partido, os três fundaram a IC, partido que pronto aderiu à coalizão de esquerda da Unidade Popular, somando-se ao MAPU e aos majoritários e influentes Partido Comunista e Partido Socialista. A mencionada declaração assinada por Leighton e Augustín Gumucio denominou-se $A$ los cristianos de avanzada de Chile y Latinoamérica, e nela revelou-se a urgência de ambos em levar adiante um pensamento a favor da convivência democrática, dos movimentos dos trabalhadores e das lutas anticapitalistas e anti-imperialistas do continente americano. Os dois condenaram a ilegitimidade da Junta Militar instalada no Chile, "su orientación económica y social injusta y su actuación fascista y reaccionaria" (LEIGHTON \& AUGUSTÍN GUMUCIO, 1974: 2-3).

A orientação para o debate político e para as denúncias acerca da violação de direitos humanos no Chile foi a tônica de Chile-América, abordagem muito mais consistente nesse aspecto quando comparada ao conteúdo político-cultural de outros impressos do exílio chileno. Como iniciativa de seu projeto editorial, Chile-América anexou a suas páginas, como dissemos, documentos oficiais dos partidos de oposição à ditadura, bem como aqueles produzidos em abundância por organismos de direitos humanos nacionais e internacionais, contendo dados e relatos substanciais da violência política institucionalizada do Estado chileno. Sua materialidade simples, com poucas ilustrações e trabalho gráfico pouco elaborado, conferia certa identidade à linha editorial da revista, criada com o intuito central de veicular sistematicamente a denúncia à ditadura. 
A participação de intelectuais e políticos ligados ao campo do direito e/ou à esquerda católica, sobretudo na direção da revista, foi uma marca importante e distintiva de Chile-América, o que obviamente provocou clara correlação com as temáticas preferenciais apontadas. Ainda assim, a revista deu espaço a intelectuais e dirigentes políticos diversos (dentro do pensamento político de esquerda ou centro-esquerda), como Carlos Altamirano, Clodomiro Almeyda, Jorge Arrate e Pedro Vuscovic’ Bravo, do Partido Socialista; Luis Corvalán e Orlando Millas, do Partido Comunista; Luis Maira, um dos fundadores da Izquierda Cristiana; e Gabriel Valdés Subercaseaux, da Democracia Cristiana. A seção Tribuna Abierta, por exemplo, foi bastante receptiva às perspectivas táticas, estratégicas e programáticas político-partidárias da oposição, por vezes expostas em formato de entrevistas.

O prestígio de Bernardo Leighton, sobretudo, conferiu aos políticos e intelectuais mediadores responsáveis por Chile-América sua inserção em redes de solidariedade transnacional sustentadas institucionalmente pela Igreja Católica e por partidos e governos europeus, com destaque para a influência da Democracia Cristiana italiana, que governava o país. Em razão desse amparo, foi criada a Oficina de Chile Democrático, que funcionava em Roma, constituída por membros de partidos políticos e que contava com aportes financeiros oficiais, propiciando assistência e coordenação para o exílio chileno (SZNAJDER; RONIGER, 2013: 291). Os editores de ChileAmérica trabalharam muito próximos à Chile Democrático, de onde receberam suporte fundamental para a produção da revista.

Como considerações finais, pensamos que tal número significativo de iniciativas editoriais nos faz corroborar as assertivas de Loreto Rebolledo González, Noé Jitrik e Pablo Yankelevich acerca de um exílio chileno atuante e organizado, culturalmente resistente e altamente politizado. Os intelectuais chilenos, maciçamente, dentro de seus campos específicos de conhecimento e atuação, não se furtaram à união, ainda que com possíveis divergências políticas, visando uma ação prática conjunta na luta contra a ditadura e pelo restabelecimento da institucionalidade democrática no Chile. Buscou-se, outrossim, uma unidade da cultura chilena, entendendo que esta encontrava-se fragmentada pela censura imposta ao Chile e pela dispersão ocasionada pelo exílio. Assim, como defendeu Jaime Giordano em Literatura Chilena, o centro de referência de qualquer estratégia cultural e/ou política de atuação dos intelectuais opositores da ditadura foi sempre o seu país de origem, não se separando o "Chile do exterior" do “Chile do interior" (GIORDANO, 1984: 5). Essa posição foi fortemente defendida nas 
revistas Araucaria de Chile, Literatura Chilena e Chile-América, bem como nos livros publicados no exílio, consistindo em aspecto comum dos editorialismos programáticos ${ }^{6}$ dos impressos, ainda que, efetivada a união, as formas de combate à ditadura pudessem destoar.

O respaldo por parte de instituições políticas e culturais dos países que acolheram os exilados chilenos, como as universidades, os partidos políticos e as instituições governamentais, não-governamentais e religiosas na Europa, Estados Unidos, Canadá e México, sobretudo, foi de fundamental importância para que se pudessem efetivar, de maneira pungente e ressonante, as iniciativas de resistência coletiva e transnacional no exílio. Os autores, editores e colaboradores diversos na produção de livros e revistas participaram desse processo de formação e fortalecimento de redes intelectuais de resistência cultural e política no exílio não somente difundindo e organizando encontros culturais e políticos, mas proporcionando informações, denúncias, debates programáticos e criações literárias/ensaísticas que circulavam nos países anfitriões do exílio e no Chile. A comunidade intelectual e política chilena no exílio buscava, assim, refazer-se do ponto de vista identitário, cultural e político, conquistando adeptos para suas ideias e para as causas que eles defendiam, causas estas ligadas, de maneira geral, a valores de um Chile popular, democrático e socialista neste último caso em seu sentido mais amplo, caminhando para uma perspectiva cada vez mais renovada ao longo da década de 1980, em estreito diálogo com o eurocomunismo e a socialdemocracia europeia (à exceção dos comunistas chilenos).

Como afirmamos no início deste artigo, não foi nossa intenção abarcar todo universo editorial do exílio chileno. No entanto, certamente objetivamos refletir sobre algumas experiências editoriais que mostraram quão significativas foram tais atividades, sugerindo haver um caminho interessante de pesquisa acadêmica sobre o exílio. Esse caminho passa por pensar as iniciativas e práticas editoriais de maneira conjunta e comparada, destacando a relevância e especificidades dos países receptores, perspectiva potencialmente rica para a análise histórica.

\footnotetext{
${ }^{6}$ A noção de editorialismo programático, em diálogo com a proposta teórica de Fernanda Beigel, pressupõe a articulação, na produção dos impressos, entre política e cultura, com vistas à construção de uma literatura engajada. A autora se detém a refletir sobre as revistas, mas aqui estendemos essa perspectiva conceitual para pensarmos também sobre os livros. Ver BEIGEL, Fernanda (2003). Las revistas culturales como documentos de la historia latinoamericana. Utopia y Praxis Latinoamericana, Maracaibo, año 8, n. 20, pp. 105-115, marzo.
} 


\section{Fontes}

ARAUCARIA DE CHILE (1984). Ediciones Michay anuncia la aparición inmediata de la serie Libros del Meridión. Araucaria de Chile. Madrid, n. 27, pp. 223.

ARAUCARIA DE CHILE (1984). Libros de interés. Araucaria de Chile. Madrid, n. 25, pp. 224.

ARAUCARIA DE CHILE (1986). Novedades de Ediciones Michay. Araucaria de Chile.

Madrid, n. 35, pp. 222-223.

GIORDANO, Jaime (1984). Literatura y exilio. Literatura Chilena, Creación y Crítica. Los Angeles, n. 29, pp.5-6.

LEIGHTON, Bernardo \& AUGUSTÍN GUMUCIO, Rafael (1974). A los cristianos de avanzada de Chile y Latinoamerica. Chile-América. Roma, n. 1, pp. 2-3.

LITERATURA CHILENA EN EL EXILIO (1978). Ediciones de la Frontera. Literatura Chilena en el Exilio. Los Angeles, n. 6, s.p.

LITERATURA CHILENA EN EL EXILIO (1978). Editores en Canadá. Literatura Chilena en el Exilio. Los Angeles, n. 6, pp. 33.

LITERATURA CHILENA EN EL EXILIO (1978). En distribuición por Ediciones de la Frontera. Literatura Chilena en el Exilio. Los Angeles, n. 8, s.p.

ORELLANA, Carlos (1984). De la revista 'Araucaria' a los 'Libros del Meridión'. Araucaria de Chile. Madrid, n. 28, pp. 192.

VUSCOVIC'ROJO, Sergio (1978). Dawson. Araucaria de Chile. Madrid, n. 2, pp. 6177.

\section{Documentos eletrônicos}

ACERCA DE NOSOTROS (s.d.). Disponível em: http://www.cesoc.cl/nuestra-historia/. Acesso em: 11 set. 2016.

SILVA SOLAR, Julio. Revista Chile-América. Disponível em: http://www.cedocmuseodelamemoria.cl/wp-content/uploads/2013/01/revistachile-america2.pdf. Acesso em: 12 set. 2016.

\section{Referências bibliográficas}

AGAMBEN, Giorgio (2015). Meios sem fim: notas sobre a política. Belo Horizonte: Autêntica.

ALBORNOZ, César (2005). La cultura en la Unidad Popular: porque esta vez no se trata de cambiar un presidente. In: VALLEJOS, Julio Pinto (Org). Cuando hicimos historia: la experiencia de la Unidad Popular. Santiago: LOM Ediciones, pp. 147-176.

ALTAMIRANO, Carlos (2010). Introducción al volumen II. Élites culturales en el siglo XX latinoamericano. In: ALTAMIRANO, Carlos (Org.). Historia de los intelectuales en América Latina II: los avatares de la "ciudad letrada" en el siglo XX. Buenos Aires: Katz Editores, pp. 09-28.

BEIGEL, Fernanda (Directora) (2010). Autonomía y dependencia académica. Universidad e investigación científica en un circuito periférico: Chile y Argentina (1950-1980). Buenos Aires: Biblos.

(2003). Las revistas culturales como documentos de la historia latinoamericana. Utopia y Praxis Latinoamericana. Maracaibo, año 8, n. 20, pp. 105-115, marzo. 
CARREÑO, Rubí (2009). El exilio de la crítica chilena: aportes para una nueva agenda literaria. Anales de Literatura Chilena, año 10, n. 12, p. 129-144, diciembre.

COSTA, Adriane Vidal (2018). Uma proposta teórico-metodológica para o estudo de redes intelectuais latino-americanas formadas nos exílios nas décadas de $1960 \mathrm{e}$ 1970. In: COSTA, Adriane Vidal \& MAÍZ, Claudio (Orgs.). Nas tramas da "cidade letrada": sociabilidade dos intelectuais latino-americanos e as redes transnacionais. Belo Horizonte: Fino Traço, pp. 153-178.

DARNTON, Robert (2010). A questão dos livros: passado, presente e futuro. São Paulo: Companhia das Letras.

DEVÉS-VALDÉS, Eduardo (2007). Redes intelectuales en América Latina: hacia la constitución de una comunidad intelectual. Santiago: Universidad Santiago de Chile.

FERNÁNDEZ BRAVO, Álvaro (2011). Discusión bibliográfica: nuevas contribuciones para una teoría de las redes culturales. Cuad. CILHA [online], vol.12, n.1, pp. 209-215.

REBOLLEDO GONZÁLEZ, Loreto (2012). Exilios y retornos chilenos. Revista Anales. Santiago, Séptima Serie, n. 3, pp. 177-187, julio.

ROJAS MIRA, Claudia Fedora. El exilio político chileno: la Casa de Chile en México (1973-1993), una experiencia singular (2013). Universidad de Santiago de Chile, Faculdad de Humanidades.

; SANTONI, Alessandro (2013). Geografía política del exilio chileno: los diferentes rostros de la solidariedad. Perfiles Latinoamericanos, n. 41, pp. 123142, enero/junio.

RONIGER, Luis. Reflexões sobre o exílio como tema de investigação: avanços teóricos e desafios. In: QUADRAT, Samantha Viz (Org.). Caminhos cruzados: história e memória dos exílios latino-americanos no século XX. Rio de Janeiro: Editora FGV, 2011, pp. 31-61.

SUBERCASEAUX, Bernardo (2010). Historia del libro en Chile: desde la Colonia hasta el Bicentenario. Santiago: LOM Ediciones.

SZNAJDER, Mario \& RONIGER, Luis (2013). La política del destierro y el exilio em América Latina. México: Fondo de Cultura Económica.

ULIANOVA, Olga (2013). El exilio comunista chileno. Estudos Ibero-Americanos, PUCRS, v. 39, n. 2, pp. 212-236, jul./dez.

VIDAL, Paloma (2004). A história em seus restos: literatura e exílio no cone sul. São Paulo: Annablume.

YANKELEVICH, Pablo (2011). Estudar o exílio. In: QUADRAT, Samantha Viz (Org.). Caminhos cruzados: história e memória dos exílios latino-americanos no século XX. Rio de Janeiro: Editora FGV, pp. 11-30.

WEINSTEIN, Barbara (2013). Pensando a história fora da nação: a historiografia da América Latina e o viés transnacional. Revista Eletrônica da ANPHLAC, n. 14, p. 13-29, jan./jun.

Artigo recebido em 20 de agosto de 2019.

Aprovado em 13 de outubro de 2019.

DOI:10.12957/intellectus.2019.44701 